\title{
Política de patrimonio cultural en dictadura militar. El caso de la región de Magallanes 1973-1990
}

\author{
Politics of cultural heritage in military dictatorship. \\ The case of the region of Magallanes 1973-1990 \\ Luis Alegría Licuime ${ }^{a}$ Pía Acevedo MÉNDeZ ${ }^{b}$ \\ aDoctor en Estudios Americanos, Universidad de Santiago de Chile. \\ Jefe de Colecciones Museo Histórico Nacional \\ bBecaria CONICYT programa Doctorado en Arquitectura y Estudios Urbanos, \\ Pontificia Universidad Católica de Chile \\ $\varangle$ alegria.luis@gmail.com; pia.acevedo@gmail.com
}

\begin{abstract}
RESUMEN
La aspiración refundacional de la Dictadura Militar chilena (1973-1990) se internó en la cultura nacional prestando especial atención a lo que hoy entendemos como políticas del patrimonio cultural, articulando leyes y normativas, creando cargos y modificando su reglamento con el fin de dotar al Estado de mayores márgenes de acción en esta materia. En este trabajo se revisa el concepto de patrimonio cultural, los estudios culturales y del patrimonio para luego analizar los ejercicios de patrimonialización realizados en la región de Magallanes durante el período en cuestión, identificando tendencias de valorización y reconocimiento hacia ciertos fenómenos regionales y nacionales que se materializaron a través de las declaratorias de Monumento Nacional, del levantamiento de Monumentos Públicos y la difusión de algunas expresiones del folclor nacional.
\end{abstract}

PALABRAS CLAVE: patrimonio cultural, dictadura militar, Magallanes

\section{ABSTRACT}

The refoundational aspiration of the Chilean Military Dictatorship (1973-1990) was interned in the national culture paying special attention to what we understand today as cultural heritage policies, articulating laws and regulations, creating positions and modifying its regulations in order to provide the State with greater margins of action in this matter.In this work, the concept of cultural heritage, cultural studies and heritage is reviewed to later 
analyze the patrimonialization exercises carried out in the Magallanes region during the period in question, identifying tendencies of valorization and recognition towards certain regional and national phenomena they materialized through the declarations of National Monument, the removal of Public Monuments and the dissemination of some expressions of national folklore.

KEY WORDS: cultural heritage, military dictatorship, Magallanes.

\section{INTRODUCCIÓN}

Las décadas de 1970 y 1980 en América Latina se caracterizaron por la emergencia de dictaduras militares en el cono sur. Regímenes de facto, reconocidos por la implementación del terrorismo de Estado, sus graves y sistemáticas violaciones a los derechos humanos, las reformas estructurales en lo social y económico, la implementación del modelo neoliberal y un conjunto de políticas de carácter autoritario.

En este contexto, a nivel nacional, la acción cultural del régimen militar chileno se ha centrado en el conjunto de medidas de tipo represivas, expresadas en la eliminación de las producciones culturales del período de la Unidad Popular, para luego evitar y controlar cualquier atisbo de disidencia a través de la quema de libros, la censura de obras artísticas y los medios de comunicación, detenciones y despidos de intelectuales y artistas disidentes, llegando incluso el asesinato (Errázuriz \& Leiva, 2012).

Este trabajo se propone una relectura del periodo al vincular la historia económica, social y política con la historia cultural e intelectual. Así, siguiendo a Villalobos (2013), a pesar de los múltiples debates las dictaduras del cono sur, sus causas y, sobre todo, sus consecuencias, todavía son temas delicados. En este sentido:

(...) Ya sea que pongamos el acento en el uso sistemático de la tortura y de la violencia represiva en general, o que reparemos en el rediseño forzado del pacto social llevado a cabo por el fundacionalismo militar, lo cierto es que dicho periodo histórico, gruesamente inaugurado en 1964 con el golpe de Estado en Brasil y cerrado con la intervención militar en Argentina en 1976, implicó un punto de inflexión en la historia latinoamericana (p. 3).

Esta condición o aspiración refundacional es posible de reconocer en algunos discursos públicos y documentos oficiales que consignan un extenso listado de denominaciones para nombrar el Golpe de Estado y los regímenes instalados a su posterioridad: "refundación de la Nación”, “segunda independencia”, “entrada al primer mundo”, "reorganización nacional”, “contrarrevolución” (Blanco, 2010; Jara, 2011), sin embargo, estas denominaciones no fueron consideradas del todo verosímiles por parte importante de la intelectualidad tradicional 
latinoamericana que vio en estos anuncios, mucho de retórica seudoiluminista, más que una decidida acción o un proyecto político coherente. Lo anterior instaló un desprecio intelectual a todo lo que se anunciaba como "nuevo orden" o "nueva sociedad", negando su capacidad "refundadora".

De esa forma, el tópico de la refundación comenzó a ser abordado en algunos de los nuevos trabajos de investigación que revisitan el periodo ${ }^{1}$ en la década de los 2000, pero esta visión aún no ha sido tematizada de manera significativa en lo que respecta al campo de la cultura y, menos aún, al patrimonio cultural. Aun así, como hemos señalado, nuevas miradas comienzan a instalar una lectura más compleja de los años de dictadura. Moreiras (2008), por ejemplo, señala:

(...) Las dictaduras recientes del Cono Sur, después de un primer período de carácter represivo-defensivo, avanzan hacia una "refundación capitalista" inspirada por el llamado principio de mercado (Brunner, Barrios, Catalán). En el orden de las prácticas simbólicas, ese primer período, inspirado en la Doctrina de Seguridad Nacional, organiza la posibilidad misma de una consolidación disciplinaria cuya clave está en el rapto por parte del aparato estatal de los mecanismos culturales productores de sentido (p. 74).

\section{LOS ESTUDIOS CULTURALES Y LOS ESTUDIOS DEL PATRIMONIO CULTURAL.}

En América Latina, la propuesta de los Estudios Culturales (EECC) se ha configurado como un punto de cuestionamiento de una tradición académica que ha abordado la dimensión cultural y, dentro de ella, al patrimonio cultural como fenómenos accesorios de las condiciones de producción y reproducción de la sociedad, desvinculándolo de las lógicas de poder, desigualdad social y su propia configuración histórica, económica y social.

Lo anterior permite precisar que aquello que hoy se reconoce como bienes constitutivos del patrimonio cultural, en varios de los países de la región, fueron producidos en el marco de las políticas culturales de los regímenes dictatoriales. Sin embargo, en el sentido común existiría la presunción de que muchos de estos bienes provendrían de una larga tradición, es decir, desde los periodos colonial y republicano, instalándose la idea de que sus procesos de puesta en valor o patrimonialización se habrían producido durante los primeros años de las repúblicas, especialmente durante la primera mitad del siglo XIX.

De esta manera una cantidad importante de aquellos bienes que en la actualidad se reconocen como patrimoniales son resultado de la gestión y políticas de las dictaduras militares, lo que abre una discusión relevante en relación a cómo hemos caracterizado

1 Ver: Blanco, F. (2010). Desmemoria y Perversión: privatizar lo público, mediatizar lo íntimo, administrar lo privado. Santiago-Chile: Cuarto Propio; Del Sarto, A. (2010). Sospecha y Goce: genealogía de la Crítica Cultural en Chile, Santiago-Chile: Cuarto Propio; Pino-Ojeda, W. (2011). Noche y Niebla. Neoliberalismo, memoria y trauma en el Chile posautoritario. Santiago-Chile: Cuarto Propio. Para el caso de Uruguay ver: Marchesi, A. (2001). 
el campo del patrimonio cultural en nuestros países y cómo este patrimonio cultural se constituye en una pieza clave de la construcción de la hegemonía y el consenso social por parte de los grupos que propiciaron y apoyaron las dictaduras militares en el cono sur. Estas interrogantes se tornan más significativas cuando se reconoce que estos patrimonios y sus respectivos procesos de puesta en valor han sido escasamente discutidos y analizados en el marco de la emergencia de los sistemas democráticos.

De acuerdo a esto, nos parece relevante por tanto hablar más que del patrimonio cultural como algo dado, avanzar hacia la idea de un proceso histórico de construcción social, lo que significa pasar del sustantivo al verbo. En esta distinción, la memoria, en tanto uso social del pasado, es uno de los elementos que adquiere trascendencia, a tal punto, que al decir de Candaü (2002):

(...) Ningún elemento patrimonial tiene sentido fuera del vínculo con las sociedades implicadas en él. El patrimonio es el producto de un trabajo de la memoria que, con el correr del tiempo y según criterios muy variables, selecciona ciertos elementos heredados del pasado para incluirlos en la categoría de los objetos patrimoniales. Funciona eficazmente como "un aparato ideológico de la memoria". De ahí la importancia de distinguir muy bien entre la valorización del patrimonio y la patrimonialización, pues la primera es consecuencia del acto de memoria, es decir de la segunda (p. 90-91).

Así, entonces, podemos plantear la presunción de la construcción social del patrimonio, expresada en la patrimonialización y que estaría conformada de historia, tiempos y etapas que se articulan para dotar de carácter patrimonial y su valor correspondiente a las producciones culturales. Estas etapas son las de producción, distribución, intercambio y uso.

En el caso de la idea de valoración, apelamos a la categoría de capital simbólico, el que entendemos como una facultad que se encuentra presente en todos los sujetos y cuya existencia permite dar sentido a los actos de la vida. Es el capital simbólico el que transforma a estos bienes en algo más que un simple resultado de la creatividad individual, pasando a ser una representación hegemónica como pilar fundamental que vincula imaginariamente a los seres humanos con su trascendencia como cuerpo social solidario. Sin embargo, en algunos casos éste se encuentra en condición pasiva, por ello la necesidad de activación. Siguiendo con dicho razonamiento, creemos que lo que se disputa en el campo del patrimonio cultural es la capacidad simbólica de otorgar a "ciertos" bienes culturales una connotación que los resignifica como "testimonios legítimos" de la "cultura dominante", la "memoria común" y la "identidad original”, que remite a un discurso único de continuidad histórica.

En este sentido, entendemos el capital simbólico como la propiedad de reconocimiento y valoración que se vincula como red de relaciones a todos los otros capitales: físico, económico, cultural, social. Éste es percibido por los agentes sociales como generador de poder simbólico. Es el conocimiento y en el reconocimiento de los demás tipos de capital, por parte de los 
agentes sociales que disponen de determinadas categorías de percepción y de valoración lo que otorga relevancia a ciertos bienes por sobre otros, siendo este reconocimiento lo que hace que cualquier bien (material o inmaterial) se vuelva «simbólicamente eficiente, como una verdadera fuerza mágica». Así, el capital simbólico es un poder reconocido, a la vez que desconocido, y, como tal, generador de poder simbólico y de violencia simbólica (Fernández, 2013).

Otra forma de abordar el fenómeno del patrimonio cultural, remite a la noción de monumento. Para Choay (2007), la configuración del monumento, en su sentido original es que:

(...) Proveniente del latín monumentum, a su vez derivado de monere (avisar, recordar), aquello que interpela a la memoria. La naturaleza afectiva de su vocación es esencial: no se trata de constatar cosa alguna ni, tampoco, de entregar una información neutra sino de suscitar, con la emoción, una memoria viva. En este primer sentido, el término monumento denomina a todo artefacto edificado por una comunidad de individuos para acordarse de o para recordar a otras generaciones determinados eventos, sacrificios, ritos o creencias. La especificidad del monumento consiste entonces, precisamente, en su modo de acción sobre la memoria que utiliza y moviliza por medio de la afectividad, para que el recuerdo del pasado haga vibrar al diapasón del presente (p.12).

En este estudio asumiremos lo patrimonial como un fenómeno derivado de esta reconfiguración del monumento ya que, siguiendo a Choay (2007), existiría por un lado, una cualidad del monumento en su función antropológica, en tanto forma de relacionarse con el tiempo vivido, lo que, por otro lado, lo constituye en un universal cultural:

(...) Parece estar presente bajo una multiplicidad de formas, en todos los continentes y prácticamente en todas las sociedades, posean o no escritura [...] El monumento es, tanto para quienes lo edifican como para los que reciben sus mensajes, una defensa contra los traumatismos de la existencia, un dispositivo de seguridad. El monumento asegura, da confianza, tranquiliza al conjurar al ser del tiempo. Garante de los orígenes, el monumento calma la inquietud que genera la incertidumbre de los comienzos, desafío a la entropía y a la acción disolvente que el tiempo ejerce sobre todas las cosas, naturales y artificiales, el monumento intenta apaciguar la angustia de la muerte y la aniquilación (p. 12-13).

Esta argumentación del monumento como dispositivo de gestión de "la pérdida", siendo aplicable a lo patrimonial, nos parece central y sugerente para la comprensión de la problemática patrimonial de la sociedad desde la segunda mitad del siglo XX y al decir de Muriel (2007): 
(...) Sólo en una época en la que existe la percepción de una pérdida generalizada y una dificultad para consignar espacios de sentido, unido todo ello a la ruptura histórica que provoca el desmoronamiento de la idea de progreso, es donde puede aparecer el patrimonio cultural, especialmente como tecnología para manipular y gestionar sentidos, afectos, identidades (p.74).

Así, entenderemos el patrimonio cultural como un conjunto de valores, creencias y bienes que, conformados y resignificados social e históricamente, permiten construir una nueva realidad como expresión de las nuevas relaciones sociales que genera (Alegría, 2012, p.150). Siguiendo la tesis de Prats (1997), el patrimonio cultural, en tanto construcción ideológica, social y cultural, no es algo dado de manera natural sino que cada sociedad, específicamente los sectores dominantes de dicha sociedad, de acuerdo a unas pautas propias, deciden qué bienes y qué valores forman parte de él. Por su parte, Ciselli (2014) señala:

(...) los bienes patrimoniales constituyen una selección de los bienes culturales por lo que remite a símbolos, a lugares de memoria, a la identidad. Cada sociedad selecciona determinados bienes y valores que han permanecido en el tiempo y que cada grupo humano considera significativos para construir su identidad y evocar su memoria (p.2728).

Con todo, el concepto de hegemonía, devenido de Gramsci e instalado por Williams (1997) en el centro del análisis cultural desde los EECC, será imprescindible para el estudio del patrimonio cultural. De acuerdo a esto, se considera que una hegemonía dada es siempre un proceso:

(...) En la práctica, la hegemonía jamás puede ser individual. Sus estructuras internas son sumamente complejas, como puede observarse fácilmente en cualquier análisis concreto. Por otra parte (y esto es fundamental, ya que nos recuerda la necesaria confiabilidad del concepto) no se da de modo pasivo como una forma de dominación. Debe ser continuamente renovada, recreada, defendida y modificada. Asimismo, es continuamente resistida, limitada, alterada, desafiada por presiones que de ningún modo le son propias. Por tanto debemos agregar al concepto de hegemonía, los conceptos de contrahegemonía y hegemonía alternativa, que son elementos reales y persistentes de la práctica (p.34).

\section{METODOLOGÍA}

El presente estudio se caracteriza por ser un trabajo descriptivo de enfoque inductivo, donde predomina una opción metodológica mixta, siendo un estudio de caso, a través del análisis de un conjunto de variables constituidas por las tipologías del patrimonio cultural: 
declaratorias de monumentos, escultura pública y patrimonio inmaterial en la región de Magallanes entre los años 1973 a 1990. Para Collier (1993) el análisis de caso es una herramienta fundamental, ya que ayuda a agudizar el poder de descripción y perspectiva, jugando un papel fundamental en la formación de conceptos, enfocando similitudes sugestivas y contrastes entre casos. En nuestra investigación de estudio de caso, se discute la hipótesis de la "pretensión totalitaria" y la "compensación autoritaria" en las políticas públicas del patrimonio cultural, en el contexto del régimen autoritario de Chile, expresado en el proyecto de refundación simbólica en la actual región de Magallanes.

El presente trabajo corresponde a un análisis histórico, enmarcado en la idea de descubrimiento y generación de nuevas hipótesis, ya que se analizarán las políticas públicas en el ámbito del patrimonio cultural de las dictaduras del cono sur, en el caso específico de Chile y su implementación en la región de Magallanes, buscando discutir la noción hegemónica de que estos gobiernos autoritarios no poseyeron un proyecto cultural, con lo cual se propone una nueva lectura, como regímenes autoritarios con aspiración transformativa, lo que queda explicitado en su idea de refundación de la sociedad y, más en específico, en la configuración de las políticas del patrimonio cultural. Así, esta investigación de metodología mixta, complementa el análisis de caso con el análisis de variables que, como se ha mencionado para este estudio, corresponde a su núcleo central y se expresa en tres componentes propios del campo del patrimonio cultural, que son abordados de manera distintiva en el apartado de los resultados: Monumentos Nacionales; escultura pública y patrimonio inmaterial.

\section{Muestra, Técnicas de Investigación y Análisis}

Entendiendo que la noción de muestra, técnica de investigación y análisis, en ocasiones no son replicables a proyectos de investigación bajo el rótulo de EECC, para este caso abordaremos estos tópicos, ya que en el rol de investigadores de la cultura nos situamos en un espacio intelectual de discusión académica, y en especial porque desde los EECC uno de los desafíos claves es la articulación, en un marco metodológico que signifique una aproximación rigurosa a nuestro objeto de estudio, las políticas públicas del patrimonio cultural. Esto no deja de constituir un punto relevante de nuestro trabajo, ya que los EECC se han caracterizado por ser una propuesta que se define por su trabajo intelectual práctico, manifestando una preferencia por las prácticas culturales de los sujetos. Sin embargo, proponemos como estudio el análisis crítico de las políticas públicas, como polo de producción que configura dichas prácticas, aunque no abordaremos las prácticas como tal, sino que nos situaremos en el nivel de la producción discursiva de la esfera pública, el Estado, de aquello que se denomina patrimonio cultural.

En este marco es que el concepto de coyuntura cultural-histórica (Grossberg, 2012) es relevante, en tanto desde esta categoría buscamos aproximarnos a las condiciones de producción dentro de una temporalidad que se concretiza en el ejercicio de las prácticas 
culturales, constituyéndose en una estrategia específica para construir contextos (Grossberg, 2012, p. 36). Para este caso analizaremos la coyuntura cultural-histórica constituida por las políticas públicas del campo del patrimonio cultural durante la dictadura militar chilena desde 1973 a 1989. Luego, toda coyuntura cultural-histórica está conformada por la relacionalidad, teniendo en cuenta que "Ningún elemento puede ser aislado de sus relaciones, aunque esas relaciones puedan modificarse y de hecho se modifican constantemente. Cualquier acontecimiento sólo puede ser entendido de manera relacional, como una condensación de múltiples determinaciones y efectos" (Grossberg, 2012, p. 36). Así, la coyuntura culturalhistórico está constituida tanto por los elementos novedosos como por aquellos que prevalecen de la coyuntura anterior y en función de la propuesta de Williams (1997) se podría distinguir entre elemento dominante, residual y emergente.

(...) Toda cultura incluye elementos aprovechables de su pasado, pero su lugar dentro del proceso cultural contemporáneo es profundamente variable. Yo denominaría "arcaico" a lo que se reconoce plenamente como un elemento del pasado para ser observado, para ser examinado o incluso para ser ocasionalmente "revivido" de un modo deliberadamente especializado. [...] Lo residual, por definición, ha sido formado efectivamente en el pasado, pero todavía se halla en actividad dentro de un proceso cultural; no sólo -y a menudo ni eso- como un elemento del pasado, sino como un efectivo elemento del presente. [...] Es fundamental distinguir este aspecto de lo residual, que puede presentar una relación alternativa e incluso de oposición con respecto a la cultura dominante, de la manifestación activa de lo residual (siendo ésta su distinción de lo arcaico) que ha sido total o ampliamente incorporado a la cultura dominante (p. 144).

Otro aspecto fundamental del enfoque metodológico de la investigación, se refiere al análisis crítico, entendido en el marco de los EECC, como un estudio que se sitúa desde el contextualismo radical, ya que como plantea Restrepo (2012), citando a Grossberg, una de sus características es oponerse al reduccionismo teórico:

(...) La noción de contextualismo en los estudios culturales es la idea de relacionalidad, es decir, el postulado de que la relación precede -es más fundamental ontológicamentea los términos de la relación. De ahí que la categoría de "contexto" planteada en los estudios culturales, se refiera a esa densa red de relaciones constituyentes de cualquier práctica, evento o representación. Esto supone tomar distancia de una noción de contexto como simple telón de fondo o el escenario donde sucede algo, para considerarlo como su condición de posibilidad (p. 133).

Respecto de las técnicas de investigación seleccionadas para el desarrollo del artículo, utilizamos lo planteado por Tonon (2011), el análisis bibliográfico y el análisis documental. 
Entendiendo que el análisis bibliográfico se realizó a partir de la lectura selectiva, comprensiva, estratégica y crítica de libros y artículos científicos a fin de obtener insumos teóricos, conceptos y datos relevantes. Es así como las lecturas de referencias se articularon en torno a tres campos de acción:

Estudios sobre autoritarismo; estudios culturales y patrimonio cultural y estudios de la dictadura militar de Chile.

Finalmente, para el caso del análisis de las declaratorias de Monumentos Nacionales, se utilizaron las bases de datos proporcionadas por el organismo especializado. Se consultó la base de Monumentos Nacionales del Consejo de Monumentos Nacionales, disponible en línea en: www.monumentos.cl. En las esculturas públicas, el listado trabajado en esta investigación se confeccionó a partir del Catastro de Monumentos Públicos confeccionado por el Dirección de Obras Municipales de la Ilustre Municipalidad de Punta Arenas, publicado en septiembre de 2010. Complementando lo anterior se indagan decretos, leyes y normativas que regula los procesos de patrimonialización.

\section{RESULTADOS}

\section{PATRIMONIALIZACIÓN EN CONTEXTO AUTORITARIO.MONUMENTOS,} ESCULTURA PÚBLICA Y PATRIMONIO INMATERIAL EN LA REGIÓN DE MAGALLANES

\section{Normativas vinculadas al Patrimonio Cultural durante la Dictadura}

Los inicios del régimen dictatorial chileno están enmarcados por la acción represiva en el campo de la cultura, desde el mismo Golpe de Estado de 1973, se produjo un desmantelamiento abrupto, violento, dramático y feroz de todo el proyecto de la Unidad Popular. Al decir de Errázuriz y Leiva (2012)

(...) se llevó a cabo la clausura de una vasta red de organizaciones de base, la suspensión de la organicidad artístico-cultural vinculada a los partidos políticos de izquierda y centro [...] También se desmanteló el aparato estatal que mantenía una activa gestión en los circuitos populares y se reprimió a los artistas progresistas (p. 13).

Este primer momento ha sido caracterizado como la fase de instalación del régimen, que desplegó una fuerte oleada de acción represiva sobre los agentes culturales, lo que se tradujo en censura, tortura, exilio y muerte de artistas y agentes culturales, por un lado, como cierre de ciclo y por otro, se resaltaba la extensión que poseía la cruzada de los militares. Siguiendo a Errázuriz y Leiva (2012)

\section{(...) para quienes se trataba de una lucha entre el bien y el mal, entre las fuerzas}


represoras de la ideología marxista totalitaria y la restauración de la libertad como consecuencia de la intervención de las Fuerzas Armadas. Pinochet mismo fue explícito al indicar que intentaba salvar a la nación y dar un giro histórico (p. 13).

La acción refundadora del régimen se verá desplegada el año 1974, casi recién culminada la "operación de limpieza y corte", enmarcada en la idea "restauradora que pueda legitimar su accionar y proyectar el gobierno en el marco de la cruzada de la reconstrucción nacional" (Errazuriz y Leiva, 2012, p. 27). En este contexto se produjo una interesante iniciativa de regulación del campo del patrimonio cultural al proponerse el "Proyecto de Reglamento de la Ley $\mathrm{N}^{\circ} 17.288$ sobre Protección del Patrimonio Histórico y Cultural del Estado”, alojado en el Consejo de Defensa. A la fecha no existe mayor claridad sobre quiénes son los autores de dicho proyecto, sin embargo es posible suponer que su impulsor fue Enrique Campos Menéndez, asesor cultural de la Junta Militar y designado director de la Dirección de Bibliotecas, Archivos y Museos (DIBAM) en 1977.

Un extracto de dicho Reglamento da cuenta del nuevo énfasis de la conceptualización de patrimonio cultural que buscaba preservarse:

Titulo 1. De los Monumentos Nacionales del Inventario del Patrimonio Histórico-Cultural.

Artículo 2: Clasificación:

1.- Sitios arqueológicos.

2.-Sitios Históricos: lugares donde ocurrieron hechos que interesan a la historia militar, civil, constitucional, religiosa, artística, literaria, científica y económica, del país, en sus períodos, colonial y de la independencia.

3.-Sitios de interés científico.

4.-Conjuntos arquitectónicos

5.-Conjuntos mineros

6.- Monumentos arquitectónicos históricos-artísticos.

Arquitectura civil privada: incluye las casas rurales aisladas y su entorno, dependencias y parque; se entiende que esta disposición tiene especial validez en caso de las casas patronales afectadas por la Reforma Agraria.

7.-Patrimonio histórico-naval.

8.-Patrimonio Histórico Cultural Mueble

9.- Monumentos Públicos en Plazas y Paseos².

Si bien este reglamento no se llevó a cabo, resulta clave en el marco de esta investigación, pues representa una acción refundacional del nuevo régimen que tuvo otros hitos también 
esclarecedores como la creación del cargo de Asesor Cultural de la Junta de Gobierno, creado bajo el Decreto Ley N $\mathrm{N}^{\circ} 804$ de 1974. Atendiendo a los cambios políticos y sociales que el régimen militar planteaba, consideró necesario contar con una asesoría cultural que coordinará y orientará las actividades culturales pertinentes para dar un carácter reformista al sistema vigente.

Dicho cargo se perfiló como una figura dependiente directamente de la junta de gobierno y funcionó a través del Departamento Cultural de la Secretaria General de Gobierno (Arias y Gálvez, 2010, p. 172). Su misión institucional fue "asesorar, proponer las medidas políticas y programas que deban adaptarse para difundir, armonizar, perfeccionar y en general, incentivar el desarrollo cultural del país y dignificar sus medios de difusión, en términos que preserven la tradición histórico-cultural del mismo y permita proyectarla al futuro con sentido de nacionalidad" (Política Cultural del Gobierno de Chile, 1975).

Junto a la descripción de este importante cargo, en el mismo documento de la Política Cultural del Gobierno de Chile, se presenta el Convenio Cultural entre Chile y España que, en definitiva, es la intensificación de una colaboración cultural que ya provenía desde 1967. Resulta relevante destacar que en dicho convenio, adquiere una relevancia central los ámbitos patrimoniales, materializados como peticiones de la delegación chilena ${ }^{3}$, entre estos:

1. Expertos en administración de Museos, atendida la idea de que en Chile existe el propósito de transformar el actual funcionamiento de las bibliotecas, archivos y museos.

2. Expertos en Restauración de Obras de arte y documentos Históricos.

3. Intercambio de reproducciones artísticas y material informativo sobre museos. La idea es intercambiar reproducciones del patrimonio artístico de ambos países.

6. Intercambio de obras de arte, se menciona la idea de completar la sala Chile del Museo de América de Madrid enviando obras arqueológicas de Isla de Pascua, alfarería precolombina de la zona norte y de la Patagonia y Tierra del fuego ${ }^{4}$.

Esta alusión directa a piezas arqueológicas de Isla de Pascua, la Patagonia y Tierra del Fuego, nos hace situar la observación que tempranamente el régimen consideró como puntos estratégicos las zonas alejadas del territorio nacional. Lo anterior podría interpretarse desde dos perspectivas; la primera en lógica militar, como asentamientos de frontera geoestratégicos, pero que en clave patrimonial, es posible traducir a la idea de lo lejano, en tanto exótico, curioso, en una clara reminiscencia de corte gabinete de curiosidades.

La delegación chilena está integrada por: El Comandante en Jefe de la Armada, Almirante José Toribio Merino, miembro de la Junta de gobierno, Enrique Campos Menéndez, Asesor Cultural de la Junta, Germán Domínguez, Director del Departamento Cultural de la Secretaría General de Gobierno, y Carlos Sánchez, Agregado Cultural de la Embajada de Chile en España. Política Cultural del Gobierno de Chile, 1975.

4 Subrayado nuestro. 


\section{PATRIMONIALIZACIÓN EN CONTEXTO AUTORITARIO. MONUMENTOS, ESCULTURA PÚBLICA Y PATRIMONIO INMATERIAL EN LA REGIÓN DE MAGALLANES}

Un aspecto a considerar en la construcción social del patrimonio cultural, es que se encuentra determinada y condicionada por un acto político de tipo administrativo y jurídico que, objetivado en un documento público, en la forma de Acta de Declaración, consagra la nueva categoría del bien en cuestión. Por ello, nos parece relevante el análisis sobre lo que fue declarado patrimonio cultural en el contexto dictatorial, ya que este acto político y simbólico constituye uno de los ejes centrales de toda política pública del patrimonio cultural. En el caso chileno, la noción de monumento esta complementada con la de nacional, de esta forma todo monumento en Chile es nacional según la Ley por su sola condición de ser declarado monumento. Siguiendo a Mella (2011):

(...) se entiende por Monumento Nacional lo que señala el Artículo $1^{\circ}$ de la Ley $N^{\circ}$ 17.288, que sin embargo, no lo hace elaborando un concepto general; sino más bien lo hace a través de la enumeración de una serie de bienes y/o lugares que considera que deben entenderse por Monumentos Nacionales (p. 15).

Por su parte, Revetria (2015) plantea al respecto que, desde el Derecho, se ha avanzado en construir un concepto general de Monumento Nacional como bienes materiales que por interés histórico, científico, artístico y en general, cultural,

(...) han sido sometidos -mediante un procedimiento establecido o por el solo ministerio de la ley- a la protección y tuición del Estado con el objeto de que sean conservados debidamente, imponiendo, por tal motivo, a sus propietarios particulares ciertas limitaciones en su derecho de dominio (p. 15).

Con todo, consideramos que la categoría de nacional, expresada de manera singular con mayúscula- Monumento Nacional (MN)- busca establecer una diferenciación con algún otro tipo de monumento, con minúscula, que independiente de su significado simbólico o importancia histórica, científica y/o artística, carece de esta dimensión jurídica-política, otorgada desde el Estado. Ahora bien, de acuerdo a lo promulgado en la Ley 17.288, aquello lo que puede ser reconocido como Monumentos Nacionales se resume a:

(...) Los lugares, ruinas, construcciones u objetos de carácter histórico o artístico; los enterratorios o cementerios u otros restos de los aborígenes, las piezas u objetos antropo-arqueológicos, paleontológicos o de formación natural, que existan bajo o sobre la superficie del territorio nacional o en la plataforma submarina de sus aguas jurisdiccionales y cuya conservación interesa a la historia, al arte o a la ciencia; 
los santuarios de la naturaleza; los monumentos, estatuas, columnas, pirámides, fuentes, placas, coronas, inscripciones y, en general, los objetos que estén destinados a permanecer en un sitio público, con carácter conmemorativo (CMN, 1970).

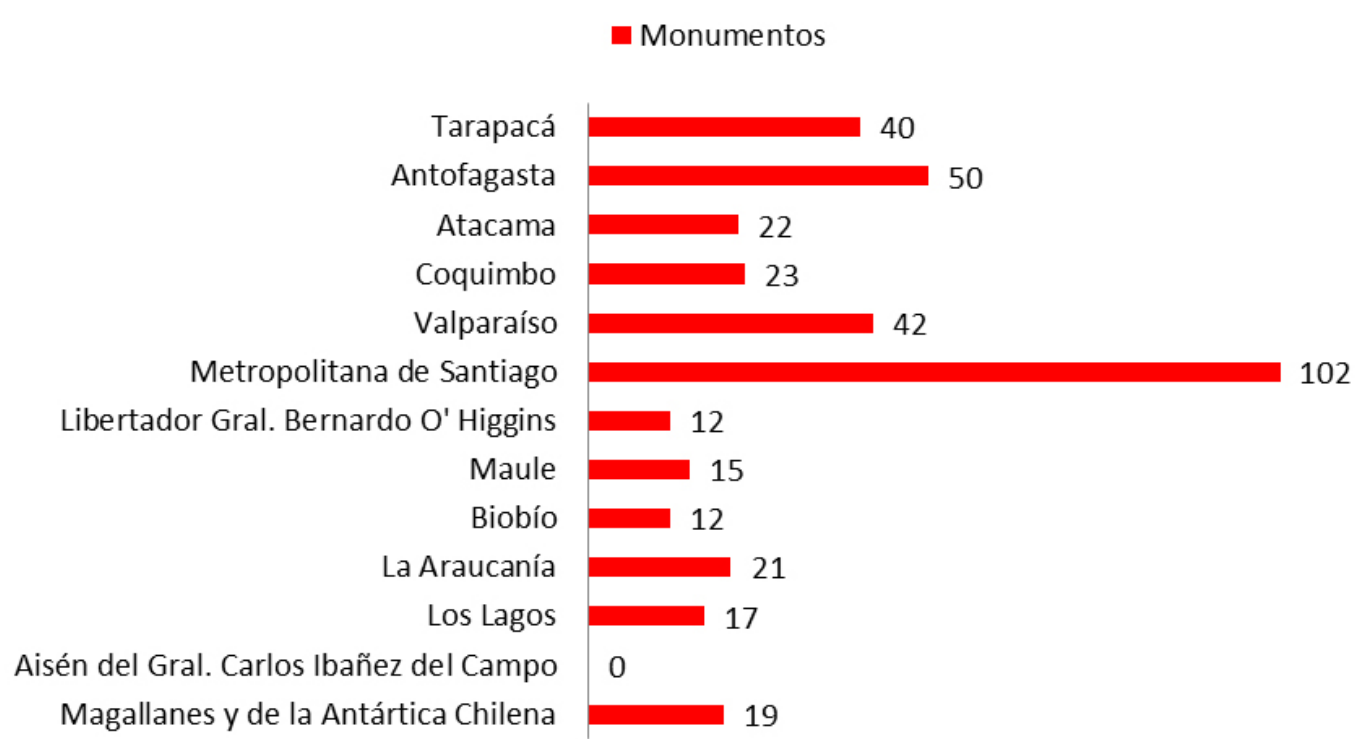

Fig. 1. catastro nacional de monumentos nacionales declarados en el período 1973-1990. Fuente: elaboración propia con datos obtenidos del sitio www.monumentos.cl

De acuerdo a esto, para el caso de estudio, las declaratorias que se produjeron en todo el país bajo la categoría de Monumento Nacional durante el período dictatorial ascendieron a 375 (Fig. 1).

En función de la cantidad de Monumentos Nacionales declarados como tal durante la dictadura es posible establecer, en primer lugar, el fenómeno del excesivo centralismo que se hace evidente con la concentración de 102 declaratorias en la Región Metropolitana, lo que representa casi un tercio del total de declaratorias. Además, en este mapeo es interesante discutir la idea de regionalización que en diversos momentos el régimen se encargó de anunciar, pero que en lo concreto no logró materializar. En segundo lugar, existe un contraste a nivel regional, tanto en el norte grande del país (Tarapacá y Antofagasta) y en la zona considerada como Patagonia (Aysén y Magallanes), ya que tres de estas regiones concentran un alto números de bienes declarados y sólo una de estas quedó marginada de la gestión patrimonial durante este período. Para el caso de la región marginada de las acciones de protección patrimonial nos referimos la región de Aysén del General Carlos Ibáñez del Campo la que durante el período 1973-1990 no obtuvo ningún tipo de declaratoria. Colindante a Aysén se encuentra la región de Magallanes, la que tuvo una situación opuesta, ya concentró diecinueve bienes reconocidos, dando cuenta del gran interés que poseía esta zona para el régimen. Creemos que en este escenario, bajo la noción de "Geopolítica" desde la perspectiva geo-estratégica, Tarapacá, Antofagasta y Magallanes tuvieron la ventaja de 
ser zona fronteriza, de ahí que para el régimen constituyera un punto clave de ocupación y vigilancia del territorio nacional. De acuerdo a esto, la Política Cultural del régimen (1975) señalaba que:

(...) La regionalización tiene que presupuestar un cambio mental del chileno, que lo haga capaz de imaginar el lugar en que vive y el contorno que lo rodea como algo propio, vinculado a sí mismo, poseedor de tradiciones, formas de vida y potencialidades culturales y materiales de gran magnitud, que lo obligan a querer su tierra.

Ahora bien, revisando la situación de los Monumentos Nacionales declarados en la región de Magallanes entre los años 1973 y 1990, tal como se dijo anteriormente, son diecinueve. De ese total de declaratorias se identifica que durante el contexto del régimen hubo una especial atención a declarar monumentos nacionales en las cuatro provincias de la región de Magallanes sin excepción, considerando al menos un Monumento en cada una de ellas. Así, para el caso de la provincia de Magallanes se declararon once Monumentos Nacionales, luego siguió Tierra del Fuego con cuatro, posteriormente la Antártica con tres y finalmente la provincia de Última Esperanza con un Monumento Nacional (Tabla 1).

Del listado de Monumentos Nacionales de Magallanes es posible advertir que se prestó mayor atención a algunos fenómenos económicos y productivos propios de la zona. En primer lugar, emergen cementerios e inmuebles vinculados a la ganadería desarrollada en la región desde fines del siglo XIX, entre ellos, la casa de Mauricio Braun Menéndez (Museo Regional de Magallanes), cementerio de Cerro Castillo, cementerio de Kon-Aikén, cementerio de Oazy Harbour, cementerio de Posesión, cementerio de Onaisín cementerio de San Sebastián y el Palacio Sara Braun.

De otro lado, se patrimonializaron bienes relacionados con otros procesos productivos de la región como la minería aurífera y la explotación petrolera, declarándose Monumento Nacional la Draga aurífera existente en Russfin y Pozo de Petróleo N 1 . Asimismo, durante el régimen se reconocieron como Monumentos Nacionales de Magallanes los restos de algunas embarcaciones que naufragaron o cumplieron un rol económico, tal es el caso de los restos de naves que indican: Proa y restos del casco del velero "Lonsdale" ex "Ville du Havre", Proa del escampavía "Yelcho" y Restos de la barca "Ambassador".

En menor medida se declararon bienes que dan cuenta de la presencia de los pueblos aborígenes en la región, destacándose el cementerio de Puerto Harris y Cementerio de Mejillones. Desde otra perspectiva, se declararon como Monumento Nacional los faros Magdalena y Posesión y las colecciones de los museos Martín Gusinde y el Museo Regional de Magallanes.

Con todo, es posible identificar que las declaratorias tuvieron una clara tendencia a poner en valor los vestigios ganaderos en la región. Esto podría argumentarse bajo la idea, según algunos autores como Martinic (2011), de que esta actividad económica propició la llegada de "los pioneros" a la zona, entendiendo que éste arribo posibilitó la dinamización 
Tabla 1. Declaratorias de Monumentos Nacionales en la región de Magallanes en el período 1973-1990.

\begin{tabular}{|c|c|c|}
\hline Nombre & Provincia & Año de declaración \\
\hline $\begin{array}{l}\text { Casa de Mauricio Braun Menéndez (Museo Regional de } \\
\text { Magallanes) }\end{array}$ & Magallanes & 1974 \\
\hline $\begin{array}{l}\text { Naves y restos de naves que indican: Proa y restos del } \\
\text { casco del velero "Lonsdale" ex "Ville du Havre" }\end{array}$ & Magallanes & 1974 \\
\hline $\begin{array}{l}\text { Naves y restos de naves que indican: Proa del escampavía } \\
\text { "Yelcho" }\end{array}$ & Antártica Chilena & 1974 \\
\hline $\begin{array}{l}\text { Naves y restos de naves que indican: Restos de la barca } \\
\text { "Ambassador" }\end{array}$ & Magallanes & 1974 \\
\hline $\begin{array}{l}\text { Lo que indica en la provincia de Magallanes: Cementerio } \\
\text { de Cerro Castillo }\end{array}$ & Última Esperanza & 1976 \\
\hline $\begin{array}{l}\text { Lo que indica en la provincia de Magallanes: Cementerio } \\
\text { de Kon-Aikén }\end{array}$ & Magallanes & 1976 \\
\hline $\begin{array}{l}\text { Lo que indica en la provincia de Magallanes: Cementerio } \\
\text { de Puerto Harris }\end{array}$ & Magallanes & 1976 \\
\hline $\begin{array}{l}\text { Lo que indica en la provincia de Magallanes: Faro } \\
\text { Magdalena }\end{array}$ & Magallanes & 1976 \\
\hline $\begin{array}{l}\text { Lo que indica en la provincia de Magallanes: Cementerio } \\
\text { de OazyHarbour }\end{array}$ & Magallanes & 1976 \\
\hline Cementerio de Posesión & Magallanes & 1976 \\
\hline Lo que indica en la provincia de Magallanes: Faro Posesión & Magallanes & 1976 \\
\hline $\begin{array}{l}\text { Lo que indica en la provincia de Magallanes: Cementerio } \\
\text { de Onaisín }\end{array}$ & Tierra del Fuego & 1976 \\
\hline $\begin{array}{l}\text { Lo que indica en la provincia de Magallanes: Cementerio } \\
\text { de San Sebastián }\end{array}$ & Tierra del Fuego & 1976 \\
\hline $\begin{array}{l}\text { Lo que indica en la provincia de Magallanes: Pozo de } \\
\text { Petróleo } \mathrm{N}^{\circ} 1\end{array}$ & Tierra del Fuego & 1976 \\
\hline $\begin{array}{l}\text { Lo que indica en la provincia de Magallanes: Draga } \\
\text { aurífera existente en Russfin }\end{array}$ & Tierra del Fuego & 1976 \\
\hline $\begin{array}{l}\text { Lo que indica en la provincia de Magallanes: Cementerio } \\
\text { de Mejillones }\end{array}$ & Antártica Chilena & 1976 \\
\hline Inmueble denominado Palacio Sara Braun & Magallanes & 1981 \\
\hline $\begin{array}{l}\text { Colecciones de todos los museos dependientes de la } \\
\text { Dirección de Bibliotecas, Archivos y Museos }\end{array}$ & Magallanes & 1987 \\
\hline $\begin{array}{l}\text { Colecciones de todos los museos dependientes de la } \\
\text { Dirección de Bibliotecas, Archivos y Museos }\end{array}$ & Antártica Chilena & 1987 \\
\hline
\end{tabular}

Fuente: elaboración propia con datos obtenidos del sitio www.monumentos.cl 
económica de la región y le otorgó los recursos para desarrollarse y posicionarse como la mayor productora de una actividad económica de impacto mundial en el país. A lo anterior se le suma que la minería aurífera y petrolera también obtuvieron un Monumento Nacional, dando cuenta que de las diecinueve declaratorias de Magallanes en el período 1973-1990 diez se vinculan directamente a los ciclos económicos de la región.

Desde otra perspectiva, hubo escaso reconocimiento a los pueblos aborígenes de Magallanes y a otras oleadas migratorias relevantes para la región como fue el arribo de los chilotes a la zona, entre los diversos fenómenos magallánicos que quedaron excluidos de este tipo de reconocimiento. Así, siguiendo a Benedetti (2011):

(...) la definición de los bienes que conforman los repertorios patrimoniales es realizada generalmente por los sectores dominantes de acuerdo a criterios propios, por lo tanto es necesario reconocer las desigualdades en su construcción y reproducción cotidiana. Así, se trata de una realidad que se va conformando a partir del choque y la interacción de los distintos intereses sociales y políticos (p. 272).

\section{Monumentos conmemorativos en dictadura.}

Espacio público y escultura en la ciudad de Punta Arenas

Dentro de las diversas tipologías de monumentos que integran el patrimonio cultural, la escultura pública de carácter conmemorativo, tiene la cualidad de configurar la versión más básica y clásica del monumento y el patrimonio cultural por su condición de síntesis entre arte, historia y espacio público. En este sentido, siguiendo a Voionmaa (2004) la escultura pública en su versión de "monumento conmemorativo, satisfizo en un principio la mentalidad historicista del siglo XIX, de la misma manera como la escultura académica o neoclásica satisfizo la añoranza de belleza clásica de la antigüedad” (p. 100).

Considerando lo anterior, el estudio de la escultura pública del periodo dictatorial es muy significativo, en parte, porque constituye la consumación del discurso nacionalista, en la configuración performativa del espacio público, combinando políticas del patrimonio y políticas urbanas. Así, lo que podríamos denominar estatuaria nacionalista, posee dos componentes clave; uno, el referente conmemorativo innegable y el otro, la noción de espacio público. De esta forma, la escultura pública, especialmente la que se localiza en el medio urbano, acaba convirtiéndose en un sistema de comunicación de gran impacto. Los patrocinadores de estas obras, en especial las administraciones públicas, descubrieron pronto que las obras escultóricas que se colocan en espacios públicos son manifestaciones culturales que resultan aprovechadas, de manera involuntaria y automática, por cantidades inmensas de público (Muruzábal 2011, p. 4).

Esta es la dimensión performativa que hemos subrayado como una constante estructural de todo nuevo régimen político autoritario. Desde allí se explica la potencia 
con la que desplegaron de manera tan evidente una política patrimonial en el contexto urbano, como monumentalización del pasado. En este sentido Maillard (2012) señala que "en el Chile autoritario se entendió lo patrimonializable como aquel legado que le daba identidad al país y que estaba conformado, fundamentalmente, por hechos históricos-militares, "héroes", y tradiciones culturales aceptadas por quienes detentaban el poder” (p. 26). Acá, nos encontramos con una dimensión interesante del monumento conmemorativo, ya que su sola presencia configura el espacio y los cuerpos, pero además, su eficacia simbólica se acrecienta, en tanto este patrimonio es puesto en escena, movilizado como plantea García Canclini o “teatralizado”, manifestándose con esto la fuerza de su condición performativa. En definitiva, la escultura pública cumple en ese sentido una función pedagógica, recordar a próceres, personajes o hechos históricos, a la generaciones venideras (Morasan 2011, p. 10).

Para el caso de la capital de la región de Magallanes, durante el período 1973-1990, se instalaron una serie de esculturas y monolitos en la ciudad bajo la categoría de Monumento Público, que tuvieron por objeto homenajear a personajes y acontecimientos significativos para Punta Arenas y para la región de Magallanes en general, según sus propios mandantes (Tabla. 2).

Tal como se puede analizar, en primer lugar, aparece la municipalidad de Punta Arenas que homenajeó la figura de "José Menéndez" y "Mauricio Braun” en los primeros años del régimen. De otro lado, entre los acontecimientos homenajeados por esta entidad, surgen el "descubrimiento del estrecho de Magallanes”, el "testimonio del festival de coros de profesores” y los agradecimientos al "Rotary Internacional”. Finalmente, el municipio de la capital magallánica también quiso reconocer a Arturo Prat con la construcción de la "Plaza Esmeralda".

Entre los otros mandantes que emergen aparece la figura de la Cruz Roja con su homenaje a "Vittorio Cuccuini", la organización de escritores regionales ensalzando la figura de "Nicomedes Guzmán”, el "Club de Leones” y el reconocimiento a su misma organización, Carabineros de Chile y la figura del "Teniente Hernán Merino Correa”, el Ejército de Chile y "Llama de La Libertad y Ignacio Carrera Pinto” y la Armada de Chile y su homenaje “A los Hijos de Chiloé”.

Finalmente, los Monumentos públicos de Punta Arenas se posicionan como una forma de categorizar eventos, acciones y personajes, permitiéndoles gozar de lugares simbólicos en el imaginario de los ciudadanos. Así, "el pasado se sedimenta en una forma monumental en medio del espacio público que genera la ilusión de una memoria común y compartida" (Sanfuentes 2011, p.282). Y en función de lo revisado, aquella memoria común y compartida que intentaron configurar algunos mandantes en la capital magallánica se relacionan con un pasado ganadero, así como también migrante y vinculado a batallas y logros de orden bélico, entre otros.

Folclor, cultura popular y patrimonio inmaterial

El término Folklore surge en Europa a mediados del siglo XIX como una palabra compuesta, que significa sabiduría del pueblo, "folk": pueblo y "lore": sabiduría. En América 
Tabla 2. Monumentos Públicos levantados en la ciudad de Punta Arenas en el período 1973-1990.

\begin{tabular}{|c|c|c|c|c|}
\hline Nombre & Emplazamiento & Mandante & $\begin{array}{l}\text { Año de } \\
\text { edificación }\end{array}$ & $\begin{array}{l}\text { Tipo de } \\
\text { construcción }\end{array}$ \\
\hline "Alfonsina Storni" & $\begin{array}{l}\text { Av. Colón / } \\
\text { Patagona. Punta } \\
\text { Arenas }\end{array}$ & $\begin{array}{l}\text { Entre las } \\
\text { Municipalidades de } \\
\text { Punta Arenas y } \\
\text { Ushuaia }\end{array}$ & 1973 & Busto \\
\hline “Jose Menéndez" & $\begin{array}{l}\text { Plaza de Muñoz } \\
\text { Gamero. Punta } \\
\text { Arenas }\end{array}$ & $\begin{array}{l}\text { Municipalidad de } \\
\text { Punta Arenas }\end{array}$ & 1975 & Busto \\
\hline "Vittorio Cuccuini" & $\begin{array}{l}\text { Av. Colón / } \\
\text { O’higgins. Punta } \\
\text { Arenas }\end{array}$ & Cruz Roja & $\begin{array}{l}18 \text { de } \\
\text { Septiembre } \\
\text { de } 1979\end{array}$ & Busto \\
\hline $\begin{array}{l}\text { "Testimonio del } \\
\text { Festival de Coros } \\
\text { de Profesores" }\end{array}$ & $\begin{array}{l}\text { Av. España / El } \\
\text { Bosque. Punta } \\
\text { Arenas }\end{array}$ & $\begin{array}{l}\text { Municipalidad de } \\
\text { Punta Arenas }\end{array}$ & $\begin{array}{l}\text { Octubre de } \\
1979\end{array}$ & Monolito \\
\hline $\begin{array}{l}\text { "Nicomedes } \\
\text { Guzmán" }\end{array}$ & $\begin{array}{l}\text { Manuel Rodríguez / } \\
\text { Pasaje Los } \\
\text { Coirones. Punta } \\
\text { Arenas }\end{array}$ & $\begin{array}{l}\text { Escritores } \\
\text { Regionales }\end{array}$ & 1980 & Monolito \\
\hline "Club De Leones" & $\begin{array}{l}\text { Av. Carlos Ibáñez } \\
\text { del Campo / } \\
\text { Acceso } \\
\text { Norte. Punta } \\
\text { Arenas }\end{array}$ & Club de Leones & 1980 & Monolito \\
\hline Camilo Henríquez" & $\begin{array}{l}\text { Av. Colón / Chiloé. } \\
\text { Punta Arenas }\end{array}$ & $\begin{array}{l}\text { El industrial Erwin } \\
\text { Neracher }\end{array}$ & $\begin{array}{l}18 \text { de } \\
\text { Septiembre } \\
\text { de } 1980\end{array}$ & Busto \\
\hline $\begin{array}{l}\text { “Teniente Hernán } \\
\text { Merino Correa” }\end{array}$ & $\begin{array}{l}\text { Av. Bulnes / } \\
\text { Enrique Abello. } \\
\text { Punta Arenas }\end{array}$ & $\begin{array}{l}\text { Carabineros de } \\
\text { Chile }\end{array}$ & $\begin{array}{l}1 \text { de Enero de } \\
1982\end{array}$ & $\begin{array}{l}\text { Busto } \\
\text { Monolito }\end{array}$ \\
\hline "Mauricio Braun" & $\begin{array}{l}\text { Av. Colón / Av. } \\
\text { Costanera. Punta } \\
\text { Arenas }\end{array}$ & $\begin{array}{l}\text { Municipalidad de } \\
\text { Punta Arenas }\end{array}$ & 1982 & $\begin{array}{l}\text { Monolito, } \\
\text { pirámide } \\
\text { truncada }\end{array}$ \\
\hline $\begin{array}{l}\text { "Llama de la } \\
\text { Libertad y Ignacio } \\
\text { Carrera Pinto" }\end{array}$ & $\begin{array}{l}\text { Av. Bulnes / } \\
\text { Comodoro Arturo } \\
\text { Merino Benítez. } \\
\text { Punta Arenas }\end{array}$ & Ejército de Chile & $\begin{array}{l}10 \text { de Agosto } \\
\text { de } 1982\end{array}$ & $\begin{array}{l}\text { Busto y } \\
\text { Monolito }\end{array}$ \\
\hline $\begin{array}{l}\text { "Descubrimiento del } \\
\text { Estrecho de } \\
\text { Magallanes" }\end{array}$ & $\begin{array}{l}\text { Av. Colon / Av. } \\
\text { Costanera. Punta } \\
\text { Arenas }\end{array}$ & $\begin{array}{l}\text { Municipalidad de } \\
\text { Punta Arenas }\end{array}$ & $\begin{array}{l}\text { Octubre de } \\
1983\end{array}$ & Escultura \\
\hline $\begin{array}{l}\text { "A los Hijos de } \\
\text { Chiloé" }\end{array}$ & $\begin{array}{l}\text { Av. Bulnes / } \\
\text { Manantiales. Punta } \\
\text { Arenas }\end{array}$ & Armada de Chile & $\begin{array}{l}21 \text { de } \\
\text { Septiembre } \\
\text { de } 1985\end{array}$ & $\begin{array}{l}\text { Mural y } \\
\text { Monolito }\end{array}$ \\
\hline "Plaza Esmeralda" & $\begin{array}{l}\text { Luis Uribe / } \\
\text { Cirujano Guzmán. } \\
\text { Punta Arenas }\end{array}$ & $\begin{array}{l}\text { Municipalidad de } \\
\text { Punta Arenas }\end{array}$ & Mayo de 1986 & Busto \\
\hline $\begin{array}{l}\text { "Rotary } \\
\text { Internacional" }\end{array}$ & $\begin{array}{l}\text { Av. España / El } \\
\text { Bosque. Punta } \\
\text { Arenas }\end{array}$ & $\begin{array}{l}\text { Municipalidad de } \\
\text { Punta Arenas }\end{array}$ & 1989 & Monolito \\
\hline
\end{tabular}

Fuente: elaboración propia con datos obtenidos del sitio www.monumentos.cl 
desde mediados del siglo XIX los Estados nacionales han intentado definir las características de las identidades nacionales, en función de ello promovieron ciertos enfoques funcionales a la tarea de construcción de naciones. Considerando que la nación es un fenómeno surgido en el siglo XIX, como parte de la constitución de los Estados modernos, es que resulta clave su estudio. Siguiendo a Ortiz (2000):

(...) Presupone que en el ámbito de un territorio determinado ocurra un movimiento de integración económica (surgimiento de un mercado nacional), social (educación de "todos" los ciudadanos), política (advenimiento del ideal democrático como elemento ordenador de las relaciones entre partidos y entre clases sociales), y cultural (unificación lingüística y simbólica de sus habitantes)" (p.46).

En la genealogía de la noción de patrimonio cultural inmaterial (PCI), según lo señalado Arispe (2006) durante la década de 1960 es posible rastrear los conceptos de folclor y tradición. De otro lado y siguiendo a Arispe (2006), en este mismo contexto se intentaron un sinnúmero de experiencias novedosas en el campo del patrimonio cultural, aunque la mayoría poco conocidas y poco exitosas, entre ellas el desarrollo de museos locales, comunitarios y escolares, que tendían a trabajar en conjunto con las comunidades locales teniendo, lamentablemente, un escaso impacto en el debate público internacional.

A lo anterior se sumó la necesidad de establecer un consenso respecto de la adopción del término "intangible" (en inglés) por las dificultades que encontraron los expertos en adoptar otros posibles, tales como folklore, patrimonio oral, cultura tradicional, cultura expresiva, modo de vida, cultura etnográfica, costumbres, cultura popular o patrimonio vivo cultural. A las dificultades epistemológicas de las definiciones de cada uno de estos términos, se unen las cargas ideológicas de los mismos, las particulares historia disciplinarias en cada país y las complicaciones para traducir conceptos tanto por lo que denotan como también en lo que connotan. Era problemático utilizar términos como "cultura tradicional" y "folklor" emanadas de un sistema anterior de mentalidad colonial (Mariano \& Endere 2013, p. 42).

Para el caso de los contextos dictatoriales, en cierta forma, es posible afirmar que fueron las propias políticas culturales de patrimonio cultural de los regímenes autoritarios las que terminaron por dejar fuera de todo uso social las nociones de "folklor y "cultura tradicional”, tanto por el sesgo nacionalista, colonialista y decimonónico que ya era complejo defender a ultranza en el marco de los revisionismos de la década de 1960, y más aún, como expresión de una ideología nacional adscrita a regímenes dictatoriales. En este sentido, la operación de refundación autoritaria se sustentó en una fuerte ideología nacional, como forma de encauzar el rumbo, dando unidad y coherencia. Según lo señalado por Benhabib (2006):

\section{(...) Las ideologías nacionales y los movimientos nacionalistas rechazan}


la otredad inherente a la raíz de toda cultura. La mayoría de las veces buscan "purgar" de los elementos impuros o foráneos y así convertirla en una totalidad. Irónicamente los nacionalismos revierten la perspectiva participante/observador, ya que los adherentes y los ideólogos de los movimientos nacionalistas intentan crear unidad forzada a partir de la diversidad, coherencia a partir de las incoherencias y homogeneidad partir de la discordancia narrativa (p. 34).

Considerando la situación de Chile, existen algunos ejemplos emblemáticos que dan cuenta del interés del régimen dictatorial por el folclor chileno. Destacable es el "Concurso de Música de Raíz Folklórica" que se comenzó a realizar en 1978 bajo la dirección de un insigne integrante del grupo "Los Huasos Quincheros". Según Donoso (2006) este concurso sería la continuación del "Concurso de la canción Tradicional Folklórica de Chile" que organizaron los "Huasos Qincheros" en 1974. La referida autora también menciona que se celebraron otros festivales, uno en 1978 cuyo objetivo fue el de celebrar la "llamada segunda independencia" y el otro en 1981 celebrado en la capital magallánica que pretendió homenajear a la "Liberación Nacional".

Por otra parte, en cada campeonato que se realizó en Chile los participantes debieron vestir la indumentaria huasa del valle central, independiente si este concurso se realizaba en zonas del país diferentes al referido valle, como efectivamente se hacía antes de la dictadura. De otro lado el folclor adquirió características del "folklore-espectáculo" (Donoso, 2006), estableciéndose esquemas universales para la danza, negando así sus interpretaciones y variaciones regionales y locales. Junto con esto, se expandió la enseñanza de este tipo de danza en las escuelas, formando los niños con el imaginario folklore=cueca=huasos, olvidando la diversidad que implicaban los dos primeros conceptos y el regionalismo del tercero (Donoso 2006, p. 127). Este último ejemplo de la cueca en Chile, nos remite a la idea de dispositivo pedagógico, recursivo y performativo de la cual nos habla Benhabib (2006).

Examinando este fragmento de los discursos culturales en periodos de dictadura constatamos que dichas experiencias no sólo se constituyen en meros paréntesis no democráticos, careciendo de toda intensión de proyectualidad, culminando sus alcances una vez restauradas los sistemas democráticos. Como hemos demostrado, en ellos si se anidó un proyecto de sociedad, se desplegaron eficaces estrategias de producción simbólica, configurando un repertorio de elementos materiales e inmateriales que constituyeron su visión del patrimonio cultural

Por su parte, desde la perspectiva de la sociedad civil, todas las iniciativas, en su mayoría, coincidían con los objetivos del régimen. En 1975 la Confederación Nacional de Conjuntos Folclóricos planteaba que los festivales folklóricos "permiten estimular la difusión y cultivo de nuestros folklore, como uno de los elementos que contribuyen a la solidaridad e integración de nuestra comunidad nacional" (Diario La Segunda, 20 de diciembre de 1974, citado en Donoso, 2006, p. 234). En el caso del Concurso Nacional 
POLÍTICA DE PATRIMONIO CULTURAL EN DICTADURA MILITAR

de Cueca, organizado por la Federación nacional de Cueca (FENAC) en la ciudad de Arica desde 1969, la Secretaría de Relaciones Culturales terminó por incorporarse a su organización, financiando directamente el evento. Además, en 1980, financió el traslado de un conjunto folklórico de la Región de Magallanes, cumpliendo de esta forma con una de las políticas del régimen militar de unir a todo el territorio nacional, en lo que se definió como la "Geopolítica”. Asimismo colaboraron en la organización y realización de varios campeonatos regionales de cueca, de donde saldrían las parejas clasificadas al campeonato nacional. También participaron en la creación de clubes comunales de cuecas, los que luego fueron traspasados para su administración a la FENAC (Donoso, 2006). Lo anterior da cuenta que la figura del huaso, la cueca, la música, entro otros componentes y, en definitiva, las diversas manifestaciones del folclor se constituyeron en los rasgos identitarios que definieron la cultura nacional bajo el régimen autoritario.

\section{CONCLUSIONES}

La actual Región de Magallanes y la Antártica chilena se constituye como una zona extrema, pero sobre todo como un espacio fronterizo y la gran puerta de acceso entre los océanos pacífico y atlántico, al continente antártico y a la Patagonia. Así, se ha ido configurando como un caso significativo respecto de la presencia y ocupación del territorio por parte del Estado chileno, lo que incluso ha intervenido en su tardía incorporación al ámbito de influencia del Estado nación chileno, recién desde mediados del siglo XIX.

En ese marco, si definimos la ocupación territorial como un ejercicio de despliegue de soberanía y construcción de Estado, que para los casos de zonas extremas y fronterizas González (2004) ha reconocido como proceso de chilenización, la dimensión simbólica constituye uno de los aspectos fundamentales. Especial relevancia adquiere esta dimensión simbólica cuando se apela discursivamente a la idea de refundación nacional, como lo hizo la última dictadura cívico-militar, en el periodo 1973 a 1990.

Esta estrategia de refundación, para el caso de Magallanes, la hemos rastreado en las políticas culturales del patrimonio que implementó el régimen dictatorial, obteniendo como resultados que del listado de Monumentos Nacionales de la región es posible advertir que se prestó mayor atención a los fenómenos económicos y productivos tradicionales, como es el caso de la ganadería. Luego siguió el turno de bienes relacionados con otros procesos productivos como la minería aurífera y la explotación petrolera.

Se puede concluir que esta patrimonialización de los vestigios ganaderos se enmarca en la idea, como señalan algunos autores regionales (Martinic 2011), en la ocupación definitiva del territorio al posibilitar la llegada de "los pioneros", entendiendo que este arribo permitió el desarrollo económico y la "efectiva ocupación” del territorio. Lo anterior de alguna forma también se enmarca en lo ocurrido con la minería aurífera, al sustentarse en la iniciativa individual y empresarial. 
Respecto de la centralidad de la actividad ganadera en la configuración identitaria de la región, es importante el rol del folclor, traducido en el apoyo a los festivales de cueca, expresión a través de la cual se entendió, casi de manera exclusiva, el conjunto de manifestaciones o prácticas culturales constitutivas del patrimonio cultural inmaterial de la región, una expresión anquilosada de la tradición.

Por otra parte, la producción petrolera marca un punto de diferenciación, ya que su vinculación estatal la sitúa en un punto crítico respecto al discurso hegemónico del régimen en torno a la preeminencia de la iniciativa individual, empresarial y competitiva. Quizás acá sea interesante expresar, como el caso de ENAP se enmarca en otros casos de empresas estatales, siendo la más emblemática la de FFCC donde, a modo de paradoja, se produce una dualidad desde la autoridad militar, ya que mientras en el mismo momento que se produjo el proceso de patrimonialización, es decir, un reconocimiento simbólico, contemporáneamente se inició la privatización y su desmantelamiento productivo, reconociéndole su relevancia histórica, pero no productiva. Así, para el caso del petróleo magallánico el primer campamento enapino, Manantiales, se cerró en el año 1978, pero dos años antes, en 1976, se había declarado como Monumento Nacional el primer pozo petrolero en sus mismas dependencias (Acevedo y Rojas 2015).

De otro lado, en un rango minoritario, se declararon bienes que dan cuenta de la presencia de los pueblos aborígenes en la región. Además, en este caso, como es posible apreciar en el convenio de colaboración suscrito con la España franquista, lo indígena se entiende en una lógica de otredad exótica, que se presume de interés para el mundo civilizado. En este sentido, hubo un escaso interés por reconocer otras oleadas migratorias relevantes para la región como fue el arribo de los chilotes a la zona, siendo otro de los diversos fenómenos magallánicos que quedaron excluidos de este tipo de reconocimiento.

En definitiva, la construcción social del patrimonio cultural en la región de Magallanes tendrá un momento de auge en el contexto del régimen dictarorial, expresado en las diversas tipologías del patrimonio, como la escultura figurativa y conmemorativa, los edificios y lugares denominados declarados $\mathrm{MN}$ y el fomento del patrimonio inmaterial por la vía del folclor. Lo preocupante es que, en la actualidad, buena parte de los bienes declarados patrimonio cultural en la dictadura militar sigue ocupando un lugar privilegiado y central en la narrativa identitaria local. Lo anterior expresado en la performatividad nacionalista y tradicionalista que creemos, a su vez, gatilla como proceso pasivo de resistencia cierta indiferencia ciudadana en los vestigios del pasado, pues se cree o piensa que esos son los únicos bienes posibles de patrimonializar. En este punto resulta necesario implementar estrategias simbólicas de desmontaje del discurso dictatorial y la necesaria resignificación del patrimonio regional en un nuevo contexto democrático.

\section{REFERENCIAS}

Acevedo, P., \& Rojas, C. (Eds.) (2015). Enapinos. Los campamentos petroleros del Fin del Mundo. 
Un patrimonial Industrial por armar. Etapa fundacional (1945-1962). Santiago: Consejo Nacional de la Cultura y las Artes.

Alegría, L. (2012). Patrimonio, museos y museología, En MARSAL, D. (Compiladora) Hecho en Chile. Reflexiones sobre el Patrimonio Cultural (145-172). Santiago: Consejo Nacional de la Cultura y las Artes.

Arias, K., \& Gálvez, C. (2010). Política Pública cultural de Chile: Revisión de las intervenciones del Estado en el campo cultural en el siglo XX. Tesis para optar al grado de Magíster en Gestión Cultural: Universidad de Chile.

Arispe, L. (2006). Los Debates Internacionales en torno al Patrimonio Cultural Inmaterial. Cuicuilco. Revista De Ciencias Antropológicas, 13(38), 11-28.

Benedetti, C. (2011). Patrimonio Cultural e identidad en la provincia de Tierra del Fuego. En C. Crespo, F. Losada, \& A. Martín (Eds.), Patrimonio. Políticas culturales y participación ciudadana (pp. 269-283). Buenos Aires: Editorial Antropofagia

Blanco, F. (2010). Desmemoria y Perversión: privatizar lo público, mediatizar lo íntimo, administrar lo privado. Chile: Cuarto Propio.

Benhabib, S. (2006). Las reivindicaciones de la cultura. Igualdad y diversidad en la era global. Argentina: Ediciones Katz.

Candaü, J. (2002). Antropología de la Memoria. España: Nueva Visión.

Choay, F. (2007). Alegoria del Patrimonio. Barcelona: Editorial Gustavo Gili.

Ciselli, G. (2014). El Patrimonio cultural: un objeto socio-jurídico disputado. En Ciselli, G. (Coord.) Patrimonio cultural: debates actuales y múltiples miradas. La ciudad de Comodoro Rivadavia bajo el prisma patrimonialista (27-38). Argentina: ediciones Vela al Viento.

Collier, S. (1993). Método Comparativo. Revista Uruguaya de Ciencia Política (5). Montevideo: Universidad de la República.

Errázuriz, L., \& Leiva, G. (2012). El Golpe Estético. Dictadura Militar en Chile. Santiago: Ocho Libro ediciones.

Donoso, K. (2006). La batalla del Folklore. Los conflictos por la representación de la cultura popular chilena en el siglo XX. Tesis para optar al grado académico de Licenciada en Historia. USACH.

Fernández, J. M. (2013). Capital simbólico, dominación y legitimidad. Las raíces weberianas de la sociología de Pierre Bourdieu. Papers. Revista de Sociología, [S.l.], 98(1), 33-60.

García Canclini, N. (1989). Culturas Híbridas. Estrategias para entrar y salir de la modernidad. México: Grijalbo.

Gobierno de Chile (1975). Política Cultural del Gobierno de Chile.1975: Publicado en el Diario Oficial 19 de diciembre de 1974.

González, S. (2004). El Dios Cautivo. Las Ligas Patrióticas en la chilenización compulsiva de Tarapacá (1910-1922.) Santiago: LOM Ediciones.

Grossberg, L. (2012). Estudios Culturales en tiempo futuro. Cómo es el trabajo intelectual que 
requiere el mundo de hoy. España: Siglo XXI.

Jara, I. (2011). Graficar una "segunda independencia": el régimen militar chileno y las ilustraciones de la editorial nacional Gabriela Mistral (1973-1976). Historia, 44(1), 131163.

Maillard, C. (2012). Construcción social del patrimonio. En D. Marsal (Ed.), Hecho en Chile. Reflexiones sobre el Patrimonio Cultural (pp. 251-289). Santiago: Consejo Nacional de la Cultura y las Artes.

Martinic, M. (2011). Recordando a un imperio pastoril: la Sociedad Explotadora de Tierra del Fuego (1893-1973). Magallania, 39(1), 5-32.

Mella, R. (2011). El caso del Navío Oriflama y la legislación sobre Monumentos Nacionales. Memoria para optar al grado de Licenciado en Cs. Jurídicas y Sociales, Universidad de Chile. Santiago de Chile.

Mercedes, M. \& Endere, M. L. (2013). Reflexiones acerca de la protección del patrimonio intangible a nivel internacional, regional y su proyección en Argentina. Dimensión Antropológica, 2(58), 33-59.

Morasan, M. (2011). La Histórica. Patrimonio, Monumentos y Escultura Pública de Concepción del Uruguay 1783-2011. Buenos Aires: Dunken.

Moreiras, A. (2008). Posdictadura y reforma del pensamiento en Richard, N. (Editora), Debates Críticos en América Latina (67-79). Santiago: Editorial Arcis/Cuarto Propio/Revista Crítica Cultural.

Muriel, D. (2007). El Patrimonio como Tecnología para la Producción y Gestión de identidades en la sociedad del conocimiento. Revista de Antropología, 19, 63-87.

Muruzábal, J. (2011). Espacios de cultura en torno a la escultura pública en Navarra (19752009). VII Congreso General de Historia de Navarra Arqueología. Historia Antigua. Historia Medieval. Historia del Arte y de la Música (Vol: I) Navarra.

Prats, L. (1997). Antropología y Patrimonio. España: Ariel.

Revetria, M. (2015). La Propiedad Monumental en Chile. Su Régimen Jurídico. Revista de Derecho Público, 21/22, 85-148.

Sanfuentes, O. (2011). Reflexiones en torno al rol del monumento en el espacio público. En Marsal, D. (2012) Hecho en Chile: reflexiones en torno al patrimonio cultura (255- 279). Santiago: Consejo Nacional de la Cultura y las Artes.

Tonon, G. (2011). La utilización del método comparativo en estudios cualitativos en ciencia política y ciencias sociales: diseño y desarrollo de una tesis doctoral. Revista Kairos, 15(27), 1-12

Villalobos, S. (2013). Soberanías en suspenso. Imaginación y violencia en América Latina. Argentina: La Cebra.

Voionmaa, F. (2004). Escultura Pública. Del Monumento conmemorativo a la Escultura Urbana. Santiago 1792-2004. Santiago: ediciones Ocho Libro.

Williams, R. (1997): Marxismo y Literatura. España: Península. 